\title{
Humanistic Landscape Construction in City Square Design
}

\author{
Yi Liling \\ College of Environmental Art Design of Changjiang Polytechnic, Wuhan China
}

\begin{abstract}
Keywords: city square design: humanistic landscape; construction
Abstract. Since 1990's, with the rapid development of city construction, the visage of city changes with each passing day. As one of the important parts of every city's public space, city square is the important reflection of the historic culture and artistic culture of this city and it is also the crucial place of communication, activities and exchanges. Therefore, city square meets the demands of different citizens. City square is derived from ancient Greece and ancient Rome two thousand years ago and is created from the demand of outdoor public activity space. What's more, the humanistic care spirit contained in city square is passed till now. In modern society, the real purpose of the design of city square is to satisfy the psychological, physiological and cultural demand of people of different ages and needs. However, with the rapid development in China, there appears a series of problems, for example: disorder of space organization, imperfection of the function, etc. which are all related to the lack of humanistic thought. Therefore, the design of city square should be based on humanistic thought which will make it more comfortable and convenient.
\end{abstract}

\section{Introduction}

As an ancient culture, city square still demonstrate its thriving vitality until now. For western countries, city square is a great tradition and an important component of western cities, which influences and witness the progress of many civilizations. With the constantly development of society, city square is not only undertake the cultural atmosphere of one city, but also gives a new space shaping of it in new period. For the masses, the significance of city square includes people's living space and it is also the sustenance and reveal of people's ideal of life. For our country, as the foreign goods of western culture, city square is constantly changing the life space of Chinese people. In the wave of city construction in the present society, city square has obviously become the important method to adjust urban spatial structure, shape city image and improve city quality, and the important platform which can improve local environment, strengthen city vitality and satisfy people's various needs. However, when we utilize western city square construction concept, some important elements and principles are neglected, which is humanistic thought. Nowadays in China, the city square design is more and more lack of humanity and the common problems of it which put forward by related scholars are unitary function, unsatisfying various groups of people's needs and oversize scale which can't show its affability [1]. For example, Nanjing Gulou Square simply purses the symmetry rule, but ignores people's demand of activity space, so children can only play on the slope protection near steps and there is no space for parents to look after and chat. The city squares like this are which lack of humanity are really common to see in China.

\section{City square and humanistic landscape}

The concept and classification of city square. In western cities, city square is with long history and it is the important place of communication and exchanges, so it is also called "City Living Room". The earliest city square appeared in the slave society in ancient Greek. At that time, it was the center of politics, culture and government as well as a trading market and it was also the important place for the interactions of humanistic culture and humanistic thought. In this context, western philosophical thought was taking root and many famous communicated in the square for which the square was obviously played an important role. In ancient Rome, city square was generally regarded as market and the place of assembly and later was also used for announcement, celebration and holding various ceremonies. In Humanity Place---Design Guide of City Open Space, square is an outdoor space 
dominated by rigid pavement with the function of wandering, sitting around, having dinner or observing the world where cars are prohibited [2]. There are maybe some trees, flowers and grasses in the square, but the main part is hard ground. If the afforested areas exceed hard ground, that is a park, rather than square.

The character of city square depends on its geographic location and environmental factor and the present city squares are partial to comprehensive ones [3], which can be divided into municipal square, memorial square, commercial plaza and entertainment square. Municipal squares provide places for group activities; memorial squares is built to memory historical figures or built in an historic event; commercial squares are common to be seen and they are usually concentrated for shopping; entertainment squares are mainly provide places for rest, entertainment and holding various plays.

Concept of humanistic landscape. "Humanity" is derived from "humanism" in Italian Renaissance in 14th century which concerned with people and humanity [4]. The application of humanism in city square landscape design in modern society refers to that it should pay attention to the relationship between men and nature, emphasize the harmony between men and nature, men and men and the pleasant square spatial organization and spatial form which make the demands can be realized by humanistic landscape, including the satisfaction of vision, mental and spirit. All of these must be embodied by the humanistic design in each part of city square landscape.

\section{Principles of city square landscape design}

(1) The principle of ecology

The principle of ecology is the one that sustainable development concept must abide by. As a city's name card, the city square landscape design must keep and develop ecological concept.

(2) The principle of integrity

A city square landscape is composed by many factors, therefore, no matter the inner space or outer space should insure its aesthetics and attraction [5]. Consequently, in the process of design, we should consider the whole part of the square, make every landscape factor are harmonious and unity with each other and reach an ideal effect.

(3) The principle of culture

City square is a gathering place, so in the landscape design, we should start from the history of the city and put them in the design, only this can strengthen the city square landscape vitality.

(4) The principle of humanity

Every landscape in city square should be attracted and satisfy the needs of people's society and be of sense of security. The suitable site in this city can provide a place for relieving pressure and is helpful for health and good emotion. The landscape of city square should attracts different groups of people and ensure each group will not influence each other. What's more, peak-hour, sunlight and wind should also be considered, only this can people have a comfortable place to take a rest and children and the disabled use it conveniently.

(5) The principle of relevance

In the design of square landscape, traditional factors and modern factors should be combined together by adopting modern methods to reflect modern characters..

\section{Construction strategy of humanistic landscape in city square}

In broad themes, the city square landscape is composed of different landscape factors, such as afforestation, small garden ornaments, signals, public toilet [6], etc. which will be added and reduced according to the real situation. Generally speaking, a humanistic square landscape is combined with these different factors through design principles, thereby forming humanistic square landscape.

(1) Landscaping of square.The afforestation of city square follows the design principles of rich variety and well arrange and the tradition city square is general no afforestation, mainly including rigid pavement and building [7]. However, no matter how large the modern square is, afforestation 
should be considered and the caring for men and nature of city square landscape design should be embodied. In the afforestation design of city square landscape, diversified planting can be adopted to improved increase the utilization value of the square and strengthen the feeling of light, smell, color and sound. For the plants chosen in the sunken plaza, we should notice that whether these plants will grow to the height of pavement surface; grass area can adopt slope and elevation to improve the sight condition which form an amiable small scale space rather than open grassland; multiple annual flowers, perennials, shrubs and arbors can be chosen.

(2) Square pavement. Many well-known squares in the world left deep impression on people because of their delicate pavement which is the key point in city square design, for example: Rome municipal square designed by Michelangelo [8]. Therefore, when designing the city square landscape, we should pay more attention to the function of pavement to the composition of square space rather than the grade of paving materials. Square bricks are being used in most of the time, but its style and color are monotonous. Actually concrete is a kind of first-rate and convenient paving material which can create many textures and color shock, especially the emerging concrete stamping technology and the suitable use of color asphalt concrete can produce good visual effect. City square belongs to outdoor space, thus through the change of color, special scale can be designated and the anti-slip function in snow or rainy day can be noticed.

(3)Particular treatment of square small garden ornaments. Some public artworks which will create an interactive environment can be arranged in city square to improve the communication between people. The proportion of public artworks and square should be noticed and their location can't influence gallery and sight. Some involved sculpture can be designed for people to climb, and even mold their shapes. Fountain is an important small garden ornament in square which can not only for visiting, but also make people participate in it. Seats are the most neglected part in square. When we design the seat, illumination and overshadow should be considered as well as the combination with other small garden ornaments and the arrangement of seats should also satisfy different people's needs. In addition, some prompt message, identifications, trash bins and the location should be designed reasonably.

\section{Conclusion}

As the important part of city square which is the name card showing the outside, city square landscape influences the progress of a city. Although there are many types of city square and the functions and characters of each square are different, the humanistic landscape design is really important no matter in commercial square, politic square or cultural square. This can reflect the humanistic caring of the masses and it is also the good embodiment of city civilization process. Therefore, at the beginning of the design of humanistic landscape design, people's needs should be analyzed. Only understand the psychology and activity of people, can we specially design the humanistic landscape. Consequently, related designers should start from this point to design more humanistic city square landscape.

\section{References}

[1] Ma Teng. Analysis of the construction of humanistic landscape in city square design [J]. INTERIOR DESIGN China, 2016, (11):165-165.

[2] Chen Kean. Exploration of Chinese city square design [J].Beauty and Time.City, 2015, (11):114-115.

[3] Zhang $\mathrm{Xu}$, Li Cheng. Exploration of city square design in the view of regional features and cultural connotations [J]. Urban Architecture, 2014,(2):14-14.

[4] Xiang Boxun. Discussion of the misunderstanding and growing trend of Chinese city square design [J]. Art Educational Design, 2015,(16):71. 
[5] Xie Chunguo. Discussion of the culture and inherit of city square design [J]. Hunan Decoration, 2015,30(4):64-65,67.

[6] Fan Fei. Discussion of city square design [J]. Beauty and Time City, 2014,(9):14-15.

[7] He Haifang, Zhengkan. Discussion the everyday city square design [J]. Sichuan Cement, 2015,(11):125.

[8] Li Xinran, Gao Feng. Discussion of city square humanistic construction [J]. Beauty and Time $\cdot$ City, 2016,(3):33-34. 